\title{
UMA ANÁLISE EMPÍRICA DA SENSIBILIDADE DA DEMANDA DE INVESTIMENTO A RESTRIÇÕES DE CRÉDITO NO BRASIL
}

\section{An Empirical analisys of the sensitivity of investment demand to credit restrictions in Brazil}

Fernando Nascimento Oliveira

Doutorado em Economia pela Pontifícia Universidade Católica do Rio de Janeiro, Mestrado em Economia pela Pontifícia Universidade Católica do Rio de Janeiro, e Graduação em

Engenharia Elétrica pela Pontifícia Universidade Católica do Rio de Janeiro fernando.nascimento@bcb.gov.br

Guilherme Cunha Mestre Profissional Ibmec/RJ guilherme.cunha@gmail.com

Submissão: $14 / 08 / 2012$

Aprovação: 06/12/2012

\begin{abstract}
Resumo
Este artigo analisa a sensibilidade do investimento de empresas brasileiras a restrições de crédito. Para tanto, foi construída um painel não balanceado de informações financeiras trimestrais de 168 empresas públicas brasileiras de 1986 a 2009. A Hipótese principal é que firmas que são mais restritas financeiramente devem depender mais de recursos próprios do que firmas com menos restrições financeiras. Os resultados empíricos, baseados em estimações em painel não balanceado com efeito fixo, corroboram esta Hipótese.
\end{abstract}

Palavras Chaves: Investimento, restrições financeiras, imperfeições de mercado, Q de Tobin.

\begin{abstract}
This study examines the sensitivity of the demand of investment of Brazilian firms to credit restrictions. To do this, a non balanced panel of quarterly financial information of 168 public companies in Brazil from 1986 to 2009 was built. The main Hypothesis suggests that firms that are financially restricted should be more dependent on their own resources for investment. The empirical results, based on unbalanced panel data with fixed effects, support this Hypothesis.
\end{abstract}

Keywords: Investment, financial constraints, market imperfections, Tobin's Q. 


\section{INTRODUÇÃO}

A pesquisa sobre as decisões de investimento das firmas foi um dos grandes temas que fomentaram o desenvolvimento da literatura econômica a partir da segunda metade do século XX. Embora o estudo do investimento corporativo tenha abordado inicialmente temas como hierarquia de financiamento e estrutura de capital (Meyer e Kuh, 1957), a publicação das proposições de Modigliani e Miller (doravante MM) ao final da década de 1950 alterou o curso da linha de pesquisa isolando as decisões de investimento de questões puramente financeiras. A abordagem teórica proposta por estes autores sugere que, em um mercado eficiente e com ausência de impostos, o valor de uma firma é medido exclusivamente pelas suas oportunidades de crescimento (refletidas no preço de seus ativos) e independente de sua estrutura de capital.

A partir do início da década de 1980, a linha de pesquisa sobre decisões de investimento retornou ao seu caminho original, quando passou a incluir em seu escopo a questão das restrições financeiras no acesso ao crédito. Os artigos publicados buscaram estender os modelos empíricos neoclássicos incorporando proxies para variáveis financeiras (como o fluxo de caixa) na tentativa de evidenciar algum tipo de dependência entre investimento e estrutura de capital.

A hipótese por trás da teoria sugere que, se a diferença entre os custos do financiamento externo e interno for pequeno, práticas de retenção de lucros não deveriam explicar variações nas contas das despesas com investimento. No entanto, caso esta diferença seja significativa, seria um indício de que tais firmas não disporiam de fontes de crédito externo de baixo custo utilizando assim recursos próprios para financiarem seus investimentos.

Fazzari, Hubbard e Petersen (1988) (doravante FHP) publicaram artigo seminal sobre o tema, relacionando os modelos tradicionais de investimento às descobertas provenientes das pesquisas sobre imperfeições de mercado, como a teoria dos contratos e os modelos de seleção adversa e risco moral ${ }^{1}$. FHP observam diferenças nos padrões de financiamento de firmas de diferentes tamanhos e formulam uma hipótese na qual os custos de financiamento interno e externo, em presença de ineficiências de mercado, não seriam perfeitamente substituíveis. Os autores estendem o modelo neoclássico tradicional baseado no Q de Tobin incluindo o fluxo de caixa da firma para capturar a sensibilidade do investimento às variações

\footnotetext{
1 Jensen e Meckling (1976) estudaram o problema de agência e o definiram como um contrato onde uma parte (o principal) atribui a outra (o agente) o direito de representá-la, outorgando ao agente o poder de decisão sobre determinados assuntos. Assumindo que ambas as partes nessa relação sejam maximizadoras de suas próprias utilidades, é intuitivo pensar que principal e agente nem sempre tenderão a agir em prol de objetivos comuns.
} 
na sua estrutura de capital. As principais descobertas sugerem que exista uma relação significativa entre investimento e alterações nos níveis de patrimônio líquido e reservas de lucro de uma firma.

A premissa metodológica utilizada consiste na divisão das amostras em grupos de firmas mais ou menos suscetíveis a restrições financeiras baseada em alguma característica estabelecida $a$ priori e na análise dos coeficientes do fluxo de caixa resultantes das regressões. Os critérios utilizados para segmentação da amostra diferem entre os artigos publicados ${ }^{23}$. A distinção entre firmas segundo a taxa de distribuição de dividendos, por exemplo, é abordada por FHP, Fazzari e Petersen (1993) e Allayanis e Mozumdar (2004). Já Hoshi, Kashyap e Scharfstein (1991) avaliam o grau de proximidade das firmas a grandes conglomerados japoneses como proxy para acesso a um maior número de fontes de financiamento. A divisão segundo a avaliação dos títulos privados e o acesso à emissão de commercial papers é abordado por Gilchrist \& Himmelberg (1995) e Calomiris, Himmelberg \& Wachtel (1994). Carpenter, Fazzari e Petersen (1994) utilizam o critério de tamanho para definir o grau das restrições financeiras enfrentadas pelas empresas.

Muito embora exista uma tendência na literatura em aceitar os resultados obtidos por autores que se basearam nesta linha metodológica, o fato das amostras serem construídas sobre pressupostos de certa forma subjetivos divide a opinião de alguns autores e levanta questionamentos acerca da aplicabilidade dos modelos utilizados e da correta interpretação dos resultados obtidos ${ }^{4}$.

O presente trabalho aplicou a técnica da regressão de dados em painel ao modelo empírico de investimento proposto por FHP em uma base de dados derivada do ECONOMÁTICA contendo informações financeiras trimestrais de 168 empresas brasileiras de capital aberto entre os anos de 1986 e 2009, utilizando uma abordagem alternativa para o critério de seleção da amostra. Ao invés de utilizar a divisão da amostra baseada em um único critério isolado, a abordagem proposta trabalhou com o conjunto interseção das firmas que satisfazem até três de alguns dos critérios de seleção utilizados entre os principais artigos já publicados na literatura: tamanho das firmas, taxa de distribuição de dividendos e acesso ao mercado de emissão de

\footnotetext{
${ }^{2} \mathrm{O}$ Anexo A apresenta uma tabela resumo dos principais artigos publicados sobre o tema apresentando as características das bases de dados e critérios de seleção utilizados.

${ }^{3}$ Costa ET AL (2008), Terra (2003), Zani e Procianoy (2005), Kirch ET al (2010), Portal ET AL (2011) sugerem também contribuições inéditas em termos de critério de classificação a priori de firmas com restrição financeira para o Brasil.

${ }^{4}$ KAPLAN e ZINGALES (1997) criticam os critérios de classificação usados por FHP e sobre a interpretação da sensibilidade do investimento ao fluxo de caixa. Maiores detalhes sobre o artigo na revisão de literatura do presente trabalho. Uma crítica mais recente também é feita por Almeida, Campelo e Weisbach (2004)
} 
títulos. A intenção foi procurar eliminar possíveis vieses de seleção presentes em outros trabalhos diminuindo o nível de incerteza acerca da elegibilidade de uma firma à categoria financeiramente restrita.

A aplicação do modelo empírico de FHP sobre esta base de dados procurou investigar a validade da Hipótese que o fluxo de caixa é um bom indicador para detectar uma correlação relevante entre investimento e retenção de lucros das firmas, evidenciando possíveis restrições financeiras no acesso ao crédito externo e a existência de uma hierarquia de capital. ${ }^{5}$

Nossos resultados empíricos principais sugerem um alto grau de dependência de recursos próprios para investimento das firmas classificadas como financeiramente restritas. Realizamos também diversos testes de robustez, alterando a especificação principal do nosso modelo e a técnica de estimação. De forma geral, os resultados obtidos com estes testes de robustez ratificam aqueles que encontramos na análise empírica principal.

Cremos que os nossas evidências são consistentes com a visão de que o mercado de crédito no Brasil apresenta muitas imperfeições, ora relacionadas aos altos custos de capital, ora relacionadas ao ainda pouco desenvolvido mercado acionário. Desta forma, os problemas enfrentados pelas empresas brasileiras para obter crédito junto às instituições financeiras têm impactos negativos relevantes sobre suas demandas de investimento.

O restante deste artigo está estruturado da seguinte forma. Na seção 2, é realizada a revisão da literatura. Na seção 3, é apresentada a base de dados. Na seção 4, é feita a análise empírica e a apresentação dos resultados. Na seção 5, apresentamos as conclusões.

\footnotetext{
5 A pesquisa ainda ampliou a abrangência do tema investigando o comportamento da hipótese de FHP para empresas situadas no mercado brasileiro. Embora este mercado já tenha sido explorado no trabalho de Esteves e Ness (2005), considera-se que o estudo aprofundado do mercado nacional possa enriquecer significativamente o entendimento do assunto em função da diversidade de seu contexto macroeconômico.
} 


\section{REVISÃO DE LITERATURA:}

\subsection{O ESTUDO DAS DECISÕES DE INVESTIMENTO}

A preocupação com o tema das decisões de investimento foi originalmente abordada por John Meyer e Edwin Kuh no livro “The Investment Decision”, publicado em 1957 (Meyer \& Kuh, 1957). Segundo os autores, a decisão de investimento de uma empresa está sujeita a uma série de motivadores que provocam diferenças de comportamento em diferentes períodos de tempo. A diferença mais proeminente seria uma clara tendência de questões relativas à liquidez e considerações financeiras influenciando as decisões de investimento no curto prazo.

Estudos semelhantes aos de Meyer e Kuh (1957), no entanto, tornaram-se cada vez mais escassos a partir do final da década de 1950 com a publicação das proposições de Modigliani e Miller (1958). MM demonstram teoricamente que, dentro das premissas assumidas, decisões reais de investimento motivadas pela maximização do valor dos acionistas seriam independentes de fatores financeiros como liquidez, endividamento e política de dividendos. Em outras palavras, a estrutura de capital de uma firma seria irrelevante nas suas decisões de investimento.

\subsection{A ABORDAGEM NEOCLÁSSICA}

As proposições de MM (assim como outras hipóteses neoclássicas) contribuíram de forma significativa para as alterações na forma como a pesquisa seria explorada a partir de então. A hipótese da irrelevância da estrutura de capital pressupunha que os financiamentos internos e externos seriam perfeitamente substitutos e o custo de capital da firma naturalmente atribuído por um mercado eficiente. Neste contexto, toda informação disponível sobre uma determinada empresa seria automaticamente refletida em seu valor de mercado e independente de questões financeiras. A decisão de investir deveria ser tomada toda a vez que a percepção do mercado sobre suas oportunidades de crescimento (refletida no valor da ação da companhia) fosse superior ao seu custo de reposição de capital. ${ }^{6}$

O artigo publicado por James Tobin (1969) trouxe à literatura de finanças a abordagem do indicador Q e contribuiu para a extensão dos modelos de investimentos existentes utilizando outra formulação sob a ótica neoclássica. Nestes modelos, a razão entre o valor de mercado de

\footnotetext{
${ }^{6}$ Hall e Jorgenson (1967) e Jorgenson e Siebert (1968) são importantes trabalhos empíricos sobre o modelo neoclássico do investimento.
} 
uma firma sobre seu custo de reposição de ativos seria a variável básica que explicaria a demanda por investimentos ${ }^{7}$.

Como consequência à unificação do racional neoclássico ao indicador $\mathrm{Q}$ de Tobin, muitos trabalhos empíricos começaram a ser produzidos com o intuito de testar a aplicabilidade do novo modelo. A principal limitação da pesquisa essencialmente neoclássica, segundo FHP, seria a premissa de uma firma representativa comum a todos os trabalhos. Esta "firma comum" não permitiria a visualização de diferenças na sensibilidade ao investimento decorrente de questões financeiras comprometendo assim a correta interpretação dos resultados.

A percepção de que as conclusões tiradas sobre os modelos de investimento tradicionais seriam questionáveis, mesmo apesar da sólida fundamentação teórica, abriu espaço para o estudo de modelos alternativos incorporando novas linhas de pesquisa recém-introduzidas à literatura de economia e finanças. A estas novas linhas de pesquisa destacam-se a teoria dos contratos, a hierarquia de financiamento e estudos sobre aceleradores financeiros que procuravam flexibilizar algumas das fortes premissas que sustentavam a teoria neoclássica.

\subsection{EXTENSÃO DO MODELO NEOCLÁSSICO INCLUINDO IMPERFEIÇÕES NOS MERCADOS DE CAPITAIS}

Os modelos neoclássicos tradicionais sugerem que as decisões de investimento seriam independentes de fatores financeiros e assumem que toda a informação sobre as firmas e intenções de seus executivos seria disponibilizada de forma homogênea por um mercado eficiente. Hubbard (1998) em sua revisão sobre os estudos a respeito do investimento e imperfeições de mercado deriva um modelo de equilíbrio parcial $^{8}$ para o investimento corporativo sugerindo que executivos possuem acesso a informações privilegiadas sobre questões relevantes da firma em níveis muito maiores do que acionistas e credores e que esta assimetria de informação conduziria a potenciais problemas de seleção adversa e risco moral ${ }^{9}$. 2.3.1 A pesquisa sobre decisões de investimento em presença de imperfeições de mercado A hipótese oriunda dos estudos sobre o problema de agência invalida a intuição da irrelevância da estrutura de capital de MM e abre espaço para pesquisas incorporando imperfeições de mercado aos modelos tradicionais.

\footnotetext{
${ }^{7}$ Esta demanda, por sua vez, traduzir-se-ia em oportunidades de investimento que seriam atribuídas à avaliação do mercado sobre o próprio estoque de capital.

${ }^{8}$ Hubbard (1998, p.4)

${ }^{9}$ Akerlof (1970) apresenta uma situação onde características importantes do agente não são observadas durante sua seleção pelo principal e que, por isso, a qualidade e/ou risco dos projetos gera um custo adicional de monitoramento provocando um desnível entre os custos de financiamento interno e externo para o mesmo.
} 
$\mathrm{O}$ artigo seminal de FHP aborda a hipótese da hierarquia de financiamento ${ }^{10}$ e sugere que o investimento corporativo depende, sim, de fatores financeiros como a disponibilidade de recursos internos e acesso aos mercados de crédito e de capitais. Os autores estendem o modelo neoclássico tradicional baseado no $\mathrm{Q}$ de Tobin e formulam uma nova hipótese associando variáveis essencialmente financeiras para explicar variações nos níveis de investimento das empresas. O modelo proposto por FHP está descrito na equação (1) abaixo:

$$
\left(\frac{I}{K}\right)_{i t}=\alpha+\beta_{1} \cdot Q_{i t}+\beta_{2} \cdot\left(\frac{F C}{K}\right)_{i t}+a_{i}+\varepsilon_{i t}
$$

Nele, $I_{i t}$ representa o montante utilizado para investimento em ativos fixos da firma, $Q_{i t}$ seria o valor do Q de Tobin médio, $F C_{i t}$ o fluxo de caixa interno e $K_{i t}$ o estoque de capital da firma $i$ no período $t$ de acordo com o método de regressão de dados em painel. Ainda, $a_{i}$ seria a componente relativa aos efeitos fixos do modelo e $\varepsilon_{\mathrm{it}} \mathrm{o}$ termo de erro, com $\mathrm{E}\left[\varepsilon_{\mathrm{it}}\right]=0$ e $\operatorname{Var}\left[\varepsilon_{\mathrm{it}}\right]=\sigma^{2}$.

FHP analisam particularidades nas decisões de investimentos de acordo com suas taxas de retenção de lucros e distribuição de dividendos. De acordo com os autores, se o custo do financiamento externo das firmas for desprezível, a taxa de retenção de lucros não deverá sugerir informações concretas a respeito do investimento. Elas simplesmente utilizarão esta forma de financiamento para cobrir seus investimentos toda vez que houver flutuações em sua estrutura de capital. Em contrapartida, caso o custo deste endividamento seja significativo, firmas que retenham boa parte de sua receita sugeririam que não existem outras formas de financiamento de baixo custo, o que mostraria uma relação de dependência entre investimentos e flutuações em seus fluxos de caixa. Assim FHP selecionam uma amostra de empresas norte-americanas contendo informações financeiras provenientes da Value Line entre os anos de 1969 e 1983 e as classificam em três grupos de acordo com suas práticas de distribuição de dividendos. Eles acreditam que o investimento de 49 firmas categorizadas como Classe 1, por possuírem taxa de distribuição de dividendos menores do que $10 \%$ e serem classificadas como financeiramente restritas, deveriam apresentar maior sensibilidade à flutuações sobre variáveis financeiras (no caso em questão o fluxo de caixa) do que firmas que distribuam parcela maior de seus lucros na remuneração de seus acionistas. Os resultados obtidos apontam fortes evidências para as hipóteses levantadas a respeito da teoria "pecking order".

\footnotetext{
${ }^{10}$ Segundo esta hipótese, o financiamento de projetos com recursos internos seria naturalmente menos custoso do que o financiamento externo sujeito a custos adicionais de informação. Esta preferência por um determinado tipo de recurso dá origem a uma hierarquia de financiamento conhecida na literatura de finanças como "pecking order". (MYERS e MAJLUF, 1984)
} 
O sentido lógico das premissas que nortearam a elaboração do modelo de FHP, alinhado aos fortes resultados obtidos reavivou o interesse da academia pelo tema das decisões de investimento. Alguns trabalhos utilizaram o mesmo modelo empírico procurando confirmar os resultados obtidos dividindo os conjuntos amostrais de acordo com outros critérios de seleção, como tamanho das firmas e o acesso ao mercado de emissão de títulos. A motivação era encontrar evidências que pudessem da mesma forma comprovar a hipótese na qual firmas mais expostas a custos de monitoramento tendem a reter maior parcela de lucros para financiamento próprio.

É o caso de Hoshi, Kashyap e Scharfstein (1991) que utilizam a abordagem de FHP dividindo uma amostra de firmas situadas no mercado japonês de acordo com o grau de relacionamento a grandes conglomerados corporativos. Os autores concluem que os níveis de investimento em firmas com laços estreitos a determinados bancos são muito menos sensíveis ao financiamento com recursos próprios do que firmas que não possuem nenhuma ligação com instituições financeiras ligadas a grandes grupos empresariais ${ }^{11}$.

Schaller (1993) também utiliza a mesma metodologia, porém sugere três novos testes baseados em características exógenas de firmas canadenses na expectativa de capturar a existência de assimetria de informação. São utilizadas a "maturidade", "concentração de propriedade" e "disponibilidade de ativos colateralizáveis" como proxy para diferentes níveis de restrições financeiras ${ }^{12}$.

Outros artigos por sua vez procuraram demonstrar a inviabilidade do modelo neoclássico evidenciando seus pontos fracos. Blundell, Bond, Devereux e Schiantarelli (1992) analisam em que medida os modelos de investimento neoclássicos utilizando o $\mathrm{Q}$ de Tobin fornecem arcabouço empírico representativo para as decisões de investimento das firmas em geral. Os resultados obtidos sugerem alta sensibilidade do indicador $\mathrm{Q}$ a erros de medida e à sua especificação (críticas de que o Q seria baseado sob premissas muito fortes). Além disso, os autores concluem que estas restrições comprometem a utilização do Q médio como proxy para o Q marginal. ${ }^{13}$

A maior parte da literatura, no entanto, deriva o modelo fundamental de FHP procurando evidências de outras variáveis financeiras na explicação do investimento. Fazzari e Petersen (1993) investigam o papel do capital de giro como primeira opção para equilibrar os níveis de

${ }^{11}$ (CHOW, SONG e KIT, 2010) conduzem trabalho semelhante para o mercado chinês avaliando a participação do Estado na economia.

${ }^{12}$ Degryse e De Jong (2006) publicam trabalho semelhante ao de Schaller investigando o mercado dinamarquês.

${ }^{13}$ Alti (2003) analisa a sensibilidade do investimento ao fluxo de caixa quando o financiamento é feito sem atrito. 
investimento das firmas em presença de restrições financeiras. Já Bond e Meghir (1994) aprofundam o tema dos efeitos de choques cíclicos na demanda analisando a sensibilidade do investimento com relação à disponibilidade de financiamento interno em resposta a choques exógenos. Carpenter, Fazzari e Petersen (1994) analisam a sensibilidade dos estoques de produção em resposta a variações na estrutura de capital e Calomiris, Himmelberg e Wachtel (1994) investigam as características das empresas emitentes de títulos commercial paper.

É importante citar o trabalho de Ness e Esteves Filho (2005) que investigam a hipótese das restrições financeiras ao investimento em uma amostra de empresas brasileiras de capital aberto utilizando o modelo fundamental de FHP incluindo o capital de giro como variável independente. ${ }^{14}$

No entanto, existem algumas limitações conceituais que levantam dúvidas sobre a precisão de resultados obtidos. As principais críticas provêm do trabalho realizado por Kaplan e Zingales (1997) que investiga a consistência das premissas subjacentes ao artigo de FHP como o critério de seleção da amostra e a eficácia do indicador fluxo de caixa para capturar relações de dependência entre investimento e uma hierarquia de financiamento ${ }^{15}$.

Almeida et al (2004) modelam a demanda de uma empresa por liquidez de modo a desenvolver um novo teste do efeito de restrições financeiras sobre as decisões de finaciamento das empresas. O efeito das restrições financeiras é capturado pela propensão da firma em poupar na forma de acúmulo de caixa. Eles estimam empiricamente a sensibilidade do fluxo de caixa ao recursos em caixa das empresas de manufatura durante o período 1971 a 2000 e encontram suporte para a sua teoria. ${ }^{16}$

Desoallier et al (2008) avaliam dois modelos comumente utilizados para dicriminar entre empresas restritas e não restritas financeiramente. Eles comparam o método de sensibilidade do fluxo de caixa do investimento e da sensibilidade do fluxo de caixa aos recursos em caixa

\footnotetext{
${ }^{14}$ Crisóstomo (2009) utiliza uma amostra de empresas não financeiras brasileiras no período de 1995 a 2006 e mostra que elas encontram dificuldades na capacidade de financiar externamente seu investimento.

${ }^{15}$ Kaplan e Zingales (1997) examinam a relação entre o investimento e fluxo de caixa (I/FC) das 49 firmas utilizadas por FHP e sugere que firmas classificadas como menos sujeitas a restrições financeiras apresentariam maiores sensibilidades para o fluxo de caixa do que firmas tidas como financeiramente restritas. A principal crítica de KZ levanta a hipótese de que o fluxo de caixa, na verdade, atuaria como proxy para oportunidades futuras de investimento e não como sinalizador para diferentes níveis de acesso ao crédito.

${ }^{16}$ Almeida, Campelo e Weisbach (2011) propõe um modelo onde as restrições do financiamento futuro levam as empresas a preferir projetos com menor payback.
} 
das firmas. Eles mostram evidências da superioridade de modelos que escolhem firmas restritas financeiras como sendo aquelas mais sensíveis ao investimento.

A situação atual da literatura sobre o tema sugere que os resultados obtidos em favor da metodologia proposta por FHP revelam evidências significativas de uma forte relação entre investimento e fluxo de caixa corroborando a hipótese da hierarquia de capital. Esta metodologia procura testar modelos de investimento tradicionais adaptados para imperfeições de mercado sobre conjuntos de amostras divididas por critérios escolhidos a priori. 


\section{METODOLOGIA DE PESQUISA}

Nossa metodologia de pesquisa é baseada na construção de uma base de dados de empresas listadas brasileiras e na aplicação de diversas técnicas estatísticas e econométricas para verificar a importância empírica de restrições financeiras sobre as decisões de investimento das firmas.

Para a construção da base de dados foram inicialmente selecionadas, utilizando a ECONOMÁTICA, empresas listadas na Bolsa de Valores de São Paulo, não financeiras e com dados trimestrais desagregados e ajustados à inflação pelo índice IPCA entre os anos de 1986 e 2009. Esta primeira triagem resultou numa amostra de 349 firmas.

Em seguida, foram descartadas empresas que não possuíam informações financeiras completas divulgadas nos últimos dez anos (entre 1999 e 2009). Dessa forma, empresas com baixo número de registros e que encerraram suas operações neste período foram eliminadas. O conjunto amostral após este descarte compreendeu 168 firmas.

Finalmente, utilizou-se a abordagem proposta por Neves e Esteves Filho (2005) para remoção de possíveis outliers. Tal abordagem propõe que sejam removidos da base firmas que apresentem registros financeiros dos indicadores utilizados (ativo total, taxa de distribuição de dividendos, fluxo de caixa e investimento fixo) fora do intervalo de mais ou menos três desvios padrão em torno da média. Após esta etapa, a amostra final conteve 168 empresas.

\subsection{CRITÉRIOS DE SELEÇÃO PARA EMPRESAS FINANCEIRAMENTE RESTRITAS}

Um dos objetivos deste trabalho é investigar a eficiência dos principais critérios de seleção da literatura no que se refere às suas capacidades de separarem empresas que enfrentam diferentes níveis de restrições financeiras ${ }^{17}$. Cada artigo estudado foi analisado com base em alguns critérios estabelecidos a priori como: período utilizado, tamanho da amostra, origem da base de dados, modelo empírico empregado, critérios de seleção e testes de robustez.

Face à proposta do artigo de apresentar uma alternativa para diminuir possíveis vieses de seleção, imaginou-se que a utilização de uma amostra que satisfaça os principais critérios da literatura ao mesmo tempo conduza a um conjunto que possa representar e diferenciar, com nível de confiança significativo, firmas classificadas como financeiramente restritas. Em outras palavras, uma análise empírica sobre firmas que representem o conjunto interseção para a categoria "financeiramente restrita" dos principais trabalhos publicados na literatura poderia contribuir para a discussão acerca da validade do modelo empírico proposto por FHP e para a teoria do investimento corporativo em presença de imperfeições de mercado.

\footnotetext{
${ }^{17} \mathrm{O}$ Anexo A apresenta um resumo dos principais estudos nos quais o presente trabalho se baseou.
} 
Sendo assim, foram selecionados três de alguns dos critérios mais utilizados nos principais artigos publicados: tamanho das firmas, taxa de distribuição de dividendos e acesso ao mercado de emissão de títulos.

O critério tamanho das firmas, apesar de ser o mais utilizado na literatura, é bastante subjetivo no que diz respeito a um limite para o valor da conta ativo total que possa determinar com confiança se uma empresa pode ser classificada como grande ou pequena. Por exemplo, Bernanke, Gertler e Gilchrist (1996) utilizam a cifra de US\$250MM (em dólares de 1991) para diferenciar entre firmas grandes e pequenas. Já Carpenter, Fazzari e Petersen (1998) utilizam US\$300MM para tal diferenciação. Gilchrist e Himmelberg (1995) e Oliveira 2009), no entanto, empregam abordagens diferentes. Estes autores utilizam a classificação por percentis para diferenciar firmas grandes das pequenas e assim aumentar o desnível entre os valores do ativo total a fim de representar com maior fidelidade esta categoria.

Neste trabalho, considerou-se como pequena uma firma cujo ativo total é inferior ou igual ao percentil $30 \%$ da distribuição em qualquer trimestre analisado. Da mesma forma, consideramos grande uma firma cujo ativo total é superior ou igual ao percentil $70 \%$ da distribuição. Após esta operação, obtivemos uma amostra resultante de 36 firmas grandes e 29 pequenas.

Com relação à taxa de distribuição de dividendos, a subjetividade na definição do critério é substancialmente menor. Este critério foi inicialmente proposto no trabalho seminal de FHP (1988) e replicado por outros autores como o Hubbard, Kashyap e Whited (1995), Kaplan e Zingales (1997), Fazzari e Petersen (1993), entre outros. A proposta é utilizar a mesma abordagem de FHP, na qual empresas que nunca pagaram mais do que $10 \%$ de seus lucros em dividendos ao longo de todo o período analisado poderiam ser consideradas como financeiramente restritas. Desta forma, a base de dados dividida pela taxa de distribuição de dividendos apresenta 151 firmas não restritas e 17 financeiramente restritas. ${ }^{18}$

Finalmente, no que compete ao acesso à emissão de títulos, foi utilizada uma derivação da abordagem de Calomiris, Himmelberg e Wachtel (1994) e Gilchrist e Himmelberg (1995). Estes autores se beneficiam da maturidade do mercado norte-americano e utilizam informações de domínio público a respeito da graduação dos títulos das empresas que o

\footnotetext{
${ }^{18}$ No Brasil, há uma restrição legal de pagamento mínimo de $25 \%$ sobre o lucro líquido de dividendos. No entanto, como mostram Novaes e Martins (2010) há evidências que esta exigência não é obedecida por muitas empresas públicas brasileiras. Além disso, os autores citam diversas brechas na legislação que levam as empresas a não obedecer esta restrição.
} 
compõem além do acesso a outros títulos negociados, como os commercial papers. A proposta aqui é classificar firmas que fazem uso da emissão de títulos como sendo não financeiramente restritas e vice-versa. Esta hipótese baseia-se na premissa de que, para utilizar tal forma de financiamento, a firma deva atender uma série de requisitos impostos pelo mercado a fim de garantir a liquidez dos títulos emitidos. Aplicando este critério, a base de dados apresentou 94 empresas não restritas e 74 restritas.

3.2 NOVA ABORDAGEM PARA A SELEÇÃO AMOSTRAL: A INTERSEÇÃO DOS PRINCIPAIS CRITÉRIOS UTILIZADOS NA LITERATURA

Em virtude da polêmica provocada pela subjetividade das premissas escolhidas a priori para determinar o grau de restrição financeira de uma firma, a sugestão aqui é investigar o comportamento do investimento em diferentes conjuntos de dados que satisfaçam a um ou mais dos critérios de seleção definidos anteriormente.

A hipótese em questão pode ser mais bem explicada da seguinte forma: uma firma classificada como pequena, que nunca distribuiu mais do que $10 \%$ de seus lucros em dividendos em toda a sua história e que nunca emitiu títulos pertenceria, com maior nível de confiança, à categoria financeiramente restrita do que firmas que satisfaçam a apenas um dos critérios de seleção.

Sendo assim, o modelo empírico utilizado no trabalho (desenvolvido na próxima seção) será testado sobre conjuntos amostrais de firmas que satisfaçam: i) apenas um dos critérios selecionados; ii) a dois dos critérios selecionados simultaneamente; iii) à totalidade dos critérios selecionados simultaneamente.

Para facilitar o entendimento, firmas classificadas por apenas um critério de seleção serão chamadas de Grupo 1. Firmas classificadas por dois critérios de seleção serão chamadas de Grupo 2 e firmas que satisfaçam os três critérios de seleção serão classificadas como Grupo 3. A Tabela 1 abaixo mostra o número de empresas restritas e não restritas financeiramente de acordo com cada um desses grupos.

Tabela 1 - Firmas que compõem as categorias "financeiramente restritas" e "não financeiramente restritas" para os três grupos de empresas construídos

O critério de seleção foi elaborado a partir de três critérios amplamente utilizados pela literatura: tamanho, taxa de distribuição de dividendos e acesso ao mercado de emissão de títulos. Depois da exclusão dos outliers a amostra conteve 168 empresas. Firmas que satisfazem um, dois e a três dos critérios foram classificadas respectivamente como Grupos 1, 2 e 3. Para associar o nível de restrição financeira ao tamanho das firmas considerou-se restritas as firmas abaixo do percentil $30 \%$ da distribuição do ativo total. Firmas com ativo total acima do percentil $70 \%$ da distribuição foram classificadas como não restritas. Firmas que nunca pagaram mais do que $10 \%$ de lucros na forma de dividendos no período de 2006 a 2009 são consideradas financeiramente restritas (FHP, 1988). Com relação ao acesso ao mercado de títulos, firmas que emitiram títulos privados pelo menos uma vez no período compreendido pela amostra foram consideradas não restritas. 


\begin{tabular}{clcc}
\hline \hline \multirow{2}{*}{ Grupo } & \multicolumn{1}{c}{ Critérios utilizados } & $\begin{array}{c}\text { Financeiramente } \\
\text { Restritas }\end{array}$ & $\begin{array}{c}\text { Não Financeiramente } \\
\text { Restritas }\end{array}$ \\
\cline { 3 - 4 } & & $\mathbf{N}$ & $\mathbf{N}$ \\
\hline \multirow{2}{*}{1} & Tamanho & 29 & 36 \\
& Distribuição de Dividendos & 17 & 151 \\
2 & Emissão de Títulos & 74 & 94 \\
3 & Tamanho / Distribuição de Dividendos & 9 & 36 \\
& Tamanho / Distribuição de Dividendos & 6 & 30 \\
\hline \hline
\end{tabular}

\subsection{ESTATÍSTICAS DESCRITIVAS}

Nas Tabelas 2 a 4, apresentamos estatísticas descritivas e testes da média das características financeiras das firmas que definimos como restritas e não restritas financeiramente de acordo com os critérios que utilizamos.

Como podemos observar, os valores apresentados apontam diferenças significativas entre as características financeiras entre as empresas que classificamos como restritas e não restritas financeiramente. Os resultados observados nos testes da média, Tabela 4, sugerem que a hipótese de igualdade entre médias de características financeiras de empresas restritas e não restritas financeiramente é fortemente rejeitada para todas as variáveis financeiras utilizadas. Estas diferenças sugerem que as premissas utilizadas para separação das firmas de acordo com cada critério de seleção são satisfatórias e garantem um bom nível de confiança quanto à representatividade da nossa base de dados.

\section{Tabela 2 Informações Financeiras das Empresas Restritas ou não Financeiramente}

A amostra é formada por um painel não balanceado de informações financeiras trimestrais de 168 empresas publicas brasileiras de 1986 a 2009. O Painel A resume as informações financeiras para os grupos de empresas classificadas como financeiramente restritas. O Painel B resume as informações financeiras para os grupos de empresas classificadas como não financeiramente restritas.

\section{Painel A - Empresas Restritas Financeiramente}

\begin{tabular}{|c|c|c|c|c|c|c|}
\hline \multirow[b]{2}{*}{ Grupo } & \multirow[b]{2}{*}{ Critérios utilizados } & \multicolumn{5}{|c|}{ Financeiramente Restritas } \\
\hline & & & Fin.CP/AT & $\begin{array}{c}\text { Rec. } \\
\text { Oper/AT }\end{array}$ & $\begin{array}{c}\text { Desp. } \\
\text { Fin/AT }\end{array}$ & $\operatorname{Ln}(\mathbf{A T})$ \\
\hline & Tamanho & 29 & $22,61 \%$ & $17,71 \%$ & $3,27 \%$ & 11,17 \\
\hline 1 & Distribuição de Dividendos & 17 & $30,81 \%$ & $13,62 \%$ & $3,43 \%$ & 11,59 \\
\hline & Emissão de Títulos & 74 & $8,93 \%$ & $15,53 \%$ & $16,31 \%$ & 12,82 \\
\hline 2 & Tamanho / Distribuição de Dividendos & 9 & $50,40 \%$ & $15,52 \%$ & $4,21 \%$ & 10,63 \\
\hline 3 & $\begin{array}{l}\text { Tamanho / Distribuição de Dividendos } \\
\text { / Emissão de Títulos }\end{array}$ & 6 & $50,86 \%$ & $11,55 \%$ & $9,69 \%$ & 10,19 \\
\hline
\end{tabular}


Painel B - Empresas não Restritas Financeiramente

\begin{tabular}{|c|c|c|c|c|c|c|}
\hline \multirow[b]{2}{*}{ Grupo } & \multirow[b]{2}{*}{ Critérios utilizados } & \multicolumn{5}{|c|}{ Não Financeiramente Restritas } \\
\hline & & & Fin.CP/AT & $\begin{array}{c}\text { Rec. } \\
\text { Oper/AT }\end{array}$ & $\begin{array}{l}\text { Desp. } \\
\text { Fin/AT }\end{array}$ & $\operatorname{Ln}(\mathbf{A T})$ \\
\hline & Tamanho & 36 & $6,97 \%$ & $10,08 \%$ & $1,37 \%$ & 16,16 \\
\hline 1 & Distribuição de Dividendos & 151 & $7,40 \%$ & $12,19 \%$ & $1,68 \%$ & 13,77 \\
\hline & Emissão de Títulos & 94 & $9,86 \%$ & $10,07 \%$ & $2,13 \%$ & 14,14 \\
\hline 2 & Tamanho / Distribuição de Dividendos & 36 & $6,97 \%$ & $10,08 \%$ & $1,37 \%$ & 16,16 \\
\hline 3 & $\begin{array}{l}\text { Tamanho / Distribuição de Dividendos / } \\
\text { Emissão de Títulos }\end{array}$ & 30 & $10,57 \%$ & $7,48 \%$ & $1,50 \%$ & 16,29 \\
\hline
\end{tabular}

Tabela 3 - Estatísticas Descritivas das Características Financeiras do Grupo 3 de Empresas Restritas Financeiramente

A amostra é formada por um painel não balanceado de informações financeiras trimestrais de 168 empresas publicas brasileiras de 1986 a 2009.

\begin{tabular}{clcccc}
\hline \hline \multirow{2}{*}{ Grupo } & Características Financeiras & \multicolumn{2}{c}{ Financeiramente Restritas } & \multicolumn{2}{c}{ Não Financeiramente Restritas } \\
\cline { 2 - 5 } & Média & Desvio Padrão & Média & Desvio Padrão \\
\hline & 10,19 & 1,41 & 16,29 & 1,13 \\
& $\begin{array}{l}\text { Ln(Ativo Total) } \\
\text { Receita Operacional / }\end{array}$ & $11,55 \%$ & $17,61 \%$ & $7,48 \%$ & $9,81 \%$ \\
$\quad \begin{array}{l}\text { Ativo Total } \\
\text { Despesas financeiras / } \\
\text { Ativo Total }\end{array}$ & $9,69 \%$ & $24,80 \%$ & $1,50 \%$ & $2,48 \%$ \\
& $\begin{array}{l}\text { Financiamento de curto prazo / } \\
\text { Ativo Total }\end{array}$ & $50,86 \%$ & $177,45 \%$ & $10,57 \%$ & $7,56 \%$ \\
\hline \hline
\end{tabular}

Tabela 4 - Testes da Média para Firmas Classificadas Quanto à Restrição Financeira para os Grupos 1, 2 e 3

A amostra é formada por um painel não balanceado de informações financeiras trimestrais de 168 empresas publicas brasileiras de 1986 a 2009. Os p-valores dos testes das diferenças entre as médias estão entre parênteses.

\begin{tabular}{|c|c|c|c|c|c|}
\hline Grupo & Critérios utilizados & $\Delta \ln (\mathrm{AT})$ & $\Delta \ln ($ EBITDA) & $\Delta \ln ($ Fin.CP) & $\Delta \ln (\operatorname{Imob})$. \\
\hline \multirow{3}{*}{1} & Tamanho & $\begin{array}{c}4.99 \\
(0.00)\end{array}$ & $\begin{array}{c}4.39 \\
(0.00)\end{array}$ & $\begin{array}{c}4.38 \\
(0.00)\end{array}$ & $\begin{array}{c}5.34 \\
(0.00)\end{array}$ \\
\hline & Distribuição de Dividendos & $\begin{array}{c}2.52 \\
(0.00)\end{array}$ & $\begin{array}{c}1.90 \\
(0.00)\end{array}$ & $\begin{array}{c}1.88 \\
(0.00)\end{array}$ & $\begin{array}{c}1.01 \\
(0.00)\end{array}$ \\
\hline & Emissão de Títulos & $\begin{array}{c}1.28 \\
(0.00)\end{array}$ & $\begin{array}{c}1.12 \\
(0.00)\end{array}$ & $\begin{array}{c}1.77 \\
(0.00)\end{array}$ & $\begin{array}{c}1.41 \\
(0.00)\end{array}$ \\
\hline
\end{tabular}


2 Tamanho / Distribuição de Dividendos

5.37

$(0.00)$

5.82

$(0.00)$
4.31

$(0.00)$

5.09

$(0.00)$
4.62

$(0.00)$

5.87

$(0.00)$
5.23

$(0.00)$

5.06

$(0.00)$

Nas seções seguintes, vamos apresentar a análise empírica e a descrição dos resultados.

\section{Análise Empírica}

A análise empírica do trabalho utilizou a técnica da regressão de dados em painel não balanceado com efeito fixo não balanceado. A metodologia empírica baseou-se no trabalho de FHP (1988) que testa a sensibilidade do investimento de uma firma às variações no seu fluxo de caixa e ao Q de Tobin, procurando demonstrar a correlação entre o investimento e a hipótese das restrições financeiras no acesso ao crédito em mercados imperfeitos. Esta hipótese sugere que dificuldades de obtenção de crédito de terceiros criaria uma hierarquia de capital onde as firmas naturalmente escolheriam inicialmente as fontes de recursos mais baratas.

$$
\left(\frac{I}{K}\right)_{i t}=\alpha+\beta_{1} \cdot Q_{i t}+\beta_{2} \cdot\left(\frac{F C}{K}\right)_{i t}+\beta_{3} \cdot\left(\frac{F C}{K}\right)_{i t} \cdot F R_{i}+a_{i}+\varepsilon_{i t}
$$

$\mathrm{Na}$ equação (2) acima, $I_{i t}$ corresponde ao investimento em ativos fixos da firma $i$ no período $t$, $K_{i t}$ ao estoque de capital da firma (ativo total), $Q_{i t}$ ao Q de Tobin e $F C_{i t}$ ao fluxo de caixa. A fim de evidenciar a influência da variável fluxo de caixa sobre o investimento das firmas, foi incluída no modelo adaptado para restrições financeiras uma variável binária $F R_{i}$ (Financeiramente Restrita) para diferenciar as firmas, atribuindo "1" para as financeiramente restritas e " 0 " caso contrário. Em seguida, $a_{i}$ corresponde à componente relativa aos efeitos fixos das firmas e $\varepsilon_{\text {it }}$ ao termo de erro, $\operatorname{com} \mathrm{E}\left[\varepsilon_{\mathrm{it}}\right]=0$ e $\operatorname{Var}\left[\varepsilon_{\mathrm{it}}\right]=\sigma^{2}$.

O cálculo do Q de Tobin foi realizado conforme convenção proposta por FHP (1988 p.194). Nela, o Q de Tobin foi calculado como na equação (3) abaixo:

$$
Q=\frac{(V+B-N)}{K}
$$

$V, B$ e $N$ correspondem respectivamente aos valores de mercado das ações da firma, da dívida e dos estoques, no início do período em questão. É importante enfatizar a crítica a respeito da eficiência do Q de Tobin médio como proxy para o Q marginal na captura de oportunidades de crescimento ${ }^{19}$.

\footnotetext{
${ }^{19}$ Hubbard (1998, p.27) discute os principais problemas de utilizar o Q de Tobin médio como proxy para o Q marginal, o construto teórico da escola neoclássica.
} 
A variável fluxo de caixa $(F C)$ por sua vez foi calculada como a soma da receita líquida da firma (após juros e impostos) e todas as deduções não financeiras incidentes sobre a receita, como depreciações e amortizações.

O objetivo é investigar a relevância estatística dos coeficientes $\beta_{1}, \beta_{2}$ e $\beta_{3}$ na explicação do investimento de uma empresa. Um $\beta_{1}$ positivo e próximo de 1 (hum) indicaria uma tendência da explicação do investimento pela teoria neoclássica (representada pelo Q de Tobin) onde as oportunidades de investimento são percebidas pelo mercado e diretamente refletidas no valor do preço dos ativos. Da mesma forma, um $\beta_{2}$ positivo e tendendo a 1 (hum) (para todas as firmas contidas no conjunto de dados, sejam elas financeiramente restritas ou não) rejeitaria a hipótese de que restrições financeiras comprometem a capacidade de captação de recursos das firmas, tornando-as dependentes de capital próprio para financiamento de projetos (representado por $\mathrm{FC} / \mathrm{K}$ ). Finalmente, $\beta_{3}$ positivo e próximo de 1 (hum) (apenas para firmas classificadas como financeiramente restritas) fortaleceria a hipótese das restrições financeiras como empecilho à captação de recursos externos por parte das firmas.

A estimação foi realizada utilizando o método dos mínimos quadrados ordinários (MQO) controlando para efeitos fixos das firmas. A Tabela 5 abaixo apresenta o resumo dos resultados obtidos.

\section{Tabela 5 - Análise de Painel não Balanceado para os Grupos 1, 2 e 3.}

A amostra é formada por um painel não balanceado de informações financeiras trimestrais de 168 empresas publicas brasileiras de 1986 a 2009. Firmas do Grupo 1 satisfazem apenas um dos critérios de seleção utilizados (tamanho, dividendos e acesso ao mercado de títulos). Firmas Grupo 2 satisfazem dois dos critérios acima. O Grupo 3 satisfazem os três critérios utilizados. Aplicou-se o modelo de investimento adaptado para restrições financeiras aos três grupos de firmas utilizando a técnica de regressão de dados em painel controlando para efeitos fixos. A coluna $\mathrm{N}$ mostra a quantidade total de firmas que compõem cada grupo. A coluna $\mathrm{Q}$ apresenta $\mathrm{o}$ coeficiente da regressão. A coluna FC apresenta o coeficiente do fluxo de caixa para a totalidade de firmas de cada grupo. A coluna FC*FR destaca a relevância do fluxo de caixa na explicação do investimento para empresas financeiramente restritas. A coluna $\mathrm{R}^{2}$ apresenta o coeficiente de determinação do modelo para os grupos testados. Entre parênteses, estão os p-valores.

\begin{tabular}{|c|c|c|c|c|c|c|}
\hline Grupo & Critérios & $\overline{\mathbf{N}}$ & $\overline{Q Q}$ & $\overline{\text { FC }}$ & FC*FR & $\overline{\mathbf{R}^{2}}$ \\
\hline \multirow{3}{*}{1} & Tamanho & 65 & $\begin{array}{l}-0.0059 \\
(0.0000)\end{array}$ & $\begin{array}{l}-0.6553 \\
(0.0000)\end{array}$ & $\begin{array}{c}0.6135 \\
(0.0000)\end{array}$ & 0.7791 \\
\hline & Distribuição de Dividendos & 168 & $\begin{array}{l}-0.0098 \\
(0.0000)\end{array}$ & $\begin{array}{l}-0.0301 \\
(0.0201)\end{array}$ & $\begin{array}{c}0.0359 \\
(0.1457)\end{array}$ & 0.6930 \\
\hline & Emissão de Títulos & 168 & $\begin{array}{l}-0.0094 \\
(0.0000)\end{array}$ & $\begin{array}{l}-0.0461 \\
(0.0110)\end{array}$ & $\begin{array}{c}0.0420 \\
(0.0664)\end{array}$ & 0.6923 \\
\hline 2 & $\begin{array}{l}\text { Tamanho / Distribuição de } \\
\text { Dividendos }\end{array}$ & 45 & $\begin{array}{l}-0.0060 \\
(0.0001)\end{array}$ & $\begin{array}{l}-0.6551 \\
(0.0000)\end{array}$ & $\begin{array}{c}0.6485 \\
(0.0000)\end{array}$ & 0.6805 \\
\hline 3 & $\begin{array}{l}\text { Tamanho / Distribuição de } \\
\text { Dividendos / Emissão de Títulos }\end{array}$ & 36 & $\begin{array}{l}-0.0056 \\
(0.0004)\end{array}$ & $\begin{array}{l}-0.6162 \\
(0.0000)\end{array}$ & $\begin{array}{c}0.6258 \\
(0.0000)\end{array}$ & 0.6329 \\
\hline
\end{tabular}


Os resultados empíricos mostram participação significativa do fluxo de caixa na explicação do investimento para empresas financeiramente restritas. À exceção das regressões Grupo 1 Distribuição de Dividendos e Grupo 1 - Emissão de Títulos, todas as outras regressões apontaram relevância estatística no nível de confiança de $95 \%$.

Em contrapartida, o fluxo de caixa, quando utilizado para todo o conjunto da amostra (sendo este composto em sua grande maioria por empresas não restritas) é significativo no nível de confiança $95 \%$, porém pouco explica o investimento. Este resultado está em linha com a teoria proposta por FHP de que empresas que são não restritas dependem menos do financiamento próprio para alavancarem seus projetos. Eles ainda apontam a baixa relevância do Q de Tobin na explicação do investimento. Isto pode ser explicado pelo problema da representatividade do Q médio como proxy para o Q marginal; pela dificuldade na construção Q de Tobin para o cenário brasileiro (Esteves e Ness, 2000, p.9); ou pela própria ineficiência do mercado nacional, fato este que corroboraria os resultados acima apresentados.

Realizamos alguns testes de robustez, para verificar se os resultados acima se mantêm. Inicialmente, estudamos a influência das crises econômicas sobre os resultados acima. Esta influência sugere que choques econômicos sobre o ciclo de negócios de um país seriam amplificados em função de piores condições do mercado de crédito. Estas condições adversas seriam motivadas, por sua vez, por problemas de agência e proporcionais à ineficiência do mercado local.

Incluímos na equação (2) como regressora a variável binária CRISES. A esta variável atribuiu-se o valor " 1 " em todos os períodos (trimestres) nos quais o país atravessou alguma crise política/econômica ou evento significativo na economia do país que tenha sido de proporções relevantes no que compete ao desenvolvimento da atividade industrial. Os eventos que incluímos são: Plano Collor (1990), Plano Real (1994), crise do México (1995), crise dos Tigres Asiáticos (1997), crise da Rússia (1998), crise cambial (1999), crise das eleições presidenciais (2002) e a crise dos EUA (2008). O modelo resultante compreendendo a variável binária proposta está descrito na equação (4):

$$
\left(\frac{I}{K}\right)_{i t}=\alpha+\beta_{1} \cdot Q_{i t}+\beta_{2} \cdot\left(\frac{F C}{K}\right)_{i t}+\beta_{3} \cdot\left(\frac{F C}{K}\right)_{i t} \cdot F R_{i}+\beta_{4} \cdot\left(\frac{F C}{K}\right)_{i t} \cdot C R I S E S_{t}+a_{i}+\varepsilon_{i t}
$$

Neste modelo, a variável $I_{i t}$ novamente representa o investimento da firma $i$ no período $t$. $K_{i t}$ representa a variável estoque de capital (ativo total), $Q_{i t}$ o $\mathrm{Q}$ de Tobin, $F C$ o fluxo de caixa da firma, $F R_{i}$ a variável binária da firma $i$ para identificar a mesma quanto à restrição financeira segundo os critérios de seleção ("1" para financeiramente restrita e "0" caso contrário).

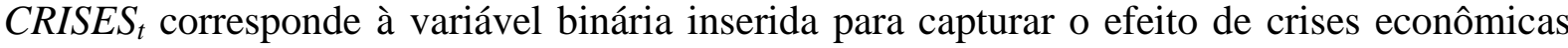


sobre o investimento das firmas, $a_{i t}$ ao termo de efeitos fixos das firmas e $\varepsilon_{\text {it }}$ ao termo de erro $\operatorname{com} \mathrm{E}\left[\varepsilon_{\mathrm{it}}\right]=0$ e $\operatorname{Var}\left[\varepsilon_{\mathrm{it}}\right]=\sigma^{2}$.

A Tabela 6 resume os resultados obtidos na estimação do painel não balanceado para os três grupos de critérios de seleção de firmas. Os resultados indicam que, em períodos de crises econômicas, a amplificação de choques macroeconômicos tende a restringir de forma geral o mercado de crédito. Esta restrição poderia ser seria explicada pelo aumento do prêmio cobrado pelas instituições financiadoras pela decisão de assumir riscos em períodos de turbulência econômica. Em tais períodos, os custos de agência são igualmente amplificados pelo aumento dos encargos cobrados sobre a exposição ao risco.

Bernanke, Gertler e Gilchrist (1996) chamam de "flight to quality" a seleção mais criteriosa de firmas para concessão de crédito em períodos onde a atividade econômica de um país é afetada por choques macroeconômicos. Segundo os autores, a amplificação dos efeitos de choques econômicos sobre empresas que enfrentam maiores custos de monitoração por credores seriam refletidos em uma dificuldade maior de obtenção de crédito junto a tais instituições. Em um período de recessão, por exemplo, seria esperado um declínio na parcela de crédito concedido às empresas mais suscetíveis a custos de monitoração como forma de reduzir a exposição ao risco das instituições financiadoras.

\section{Tabela 6 - Análise de Painel para o Modelo de Investimento de Modo a Capturar Efeitos de Crises Econômicas}

A amostra é formada por um painel não balanceado de informações financeiras trimestrais de 168 empresas publicas brasileiras de 1986 a 2009. A partir dos três grupos de firmas classificados de acordo com os critérios de seleção propostos, aplicou-se o modelo de investimento adaptado para restrições financeiras utilizando regressão de dados em painel controlando para efeitos fixos. Nesta estimação, foi incluída uma variável binária CRISES para capturar o efeito de crises econômicas ocorridas nos últimos 20 anos. A coluna $\mathrm{N}$ mostra a quantidade total de firmas que compõem cada grupo. A coluna Q apresenta o coeficiente da regressão. A coluna FC apresenta o coeficiente do fluxo de caixa para a totalidade de firmas de cada grupo. A coluna FC*FR destaca a relevância do fluxo de caixa na explicação do investimento para empresas financeiramente restritas. A coluna FC*CRISES revela a influência do investimento próprio em períodos de contração econômica quando a restrição ao crédito é mais pronunciada. A coluna $\mathrm{R}^{2}$ apresenta o coeficiente de determinação do modelo para os grupos testados. Entre parênteses, temos os p-valores.

\begin{tabular}{|c|c|c|c|c|c|c|c|}
\hline Grupo & Critérios & $\mathbf{N}$ & $\overline{Q Q}$ & FC & FC*FR & "FC*CRISES & 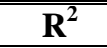 \\
\hline \multirow{3}{*}{1} & Tamanho & 65 & $\begin{array}{c}-0.0058 \\
(0.0000)\end{array}$ & $\begin{array}{l}-0.6660 \\
(0.0000)\end{array}$ & $\begin{array}{c}0.6166 \\
(0.0000)\end{array}$ & $\begin{array}{c}0.0289 \\
(0.3309)\end{array}$ & 0.7792 \\
\hline & Distribuição de Dividendos & 169 & $\begin{array}{c}-0.0093 \\
(0.0000)\end{array}$ & $\begin{array}{l}-0.1307 \\
(0.0000)\end{array}$ & $\begin{array}{c}0.1281 \\
(0.0000)\end{array}$ & $\begin{array}{c}0.1486 \\
(0.0000)\end{array}$ & 0.6941 \\
\hline & Emissão de Títulos & 168 & $\begin{array}{c}-0.0089 \\
(0.0000)\end{array}$ & $\begin{array}{c}-0.0944 \\
(0.0000)\end{array}$ & $\begin{array}{c}0.0445 \\
(0.0517)\end{array}$ & $\begin{array}{c}0.0922 \\
(0.0000)\end{array}$ & 0.6929 \\
\hline 2 & $\begin{array}{c}\text { Tamanho / Distribuição de } \\
\text { Dividendos }\end{array}$ & 45 & $\begin{array}{l}-0.0058 \\
(0.0001)\end{array}$ & $\begin{array}{l}-0.7376 \\
(0.0000)\end{array}$ & $\begin{array}{c}0.7304 \\
(0.0000)\end{array}$ & $\begin{array}{c}0.2270 \\
(0.0040)\end{array}$ & 0.6816 \\
\hline
\end{tabular}


Em um segundo teste de robustez, estimamos três modelos relacionados a empréstimos obtidos por firmas brasileiras junto ao BNDES. Primeiramente, criamos um quarto critério de seleção amostral de firmas restritas baseado na existência de empréstimo da firma junto ao BNDES durante nosso período amostral de 1986 a 2009. Consideramos firmas que obtiveram tais empréstimos de financeiramente não restritas e aquelas que não o obtiveram de financeiramente restritas. Levando em consideração a interseção deste critério com os outros três critérios de seleção, encontramos três firmas classificadas como financeiramente restritas. A sub-base construída a partir da inclusão do critério de associação ao BNDES recebeu o nome de Grupo 4.

Estimamos a equação (2) com esta sub-base e os resultados estão apresentados na Tabela 7 abaixo. Eles indicam que firmas financeiramente restritas que não possuem acesso ao crédito concedido pelo BNDES dependem mais de recursos próprios para financiamento de seus investimentos. Isto sugere a importante influência do BNDES sobre a demanda de investimento das empresas brasileiras.

\section{Tabela 7 - BNDES como Quarto Critério de Seleção}

A amostra é formada por um painel não balanceado de informações financeiras trimestrais de 168 empresas publicas brasileiras de 1986 a 2009. O primeiro teste de robustez consistiu na inclusão do quarto critério de seleção: "associação ao BNDES" (Grupo 4). Aplicou-se o modelo de investimento adaptado para restrições financeiras a este grupo utilizando regressão de dados em painel controlando para efeitos fixos. A coluna $\mathrm{N}$ mostra a quantidade de firmas que compõem o Grupo 4. A coluna $Q$ apresenta o coeficiente da regressão e o pvalor para o Q de Tobin. A coluna FC apresenta o coeficiente do fluxo de caixa para as 23 firmas do grupo e seu p-valor. A coluna FC*FR destaca a importância do fluxo de caixa na explicação do investimento para empresas financeiramente restritas. A coluna $\mathrm{R}^{2}$ apresenta o coeficiente de determinação do modelo para os grupos testados. Entre parênteses, temos os p-valores.

\begin{tabular}{|c|c|c|c|c|c|c|c|}
\hline \multirow{2}{*}{ Grupo } & \multirow{2}{*}{ Critérios } & \multicolumn{2}{|c|}{$\mathbf{N}$} & \multirow{2}{*}{$\mathbf{Q}$} & \multirow{2}{*}{ FC } & \multirow{2}{*}{ FC*FR } & \multirow{2}{*}{$\mathbf{R}^{2}$} \\
\hline & & $\mathrm{FC}$ & $\mathrm{NFC}$ & & & & \\
\hline 4 & $\begin{array}{l}\text { Tamanho / Distribuição de Dividendos / } \\
\text { Emissão de Títulos / Associação ao BNDES }\end{array}$ & 3 & 20 & $\begin{array}{l}-0.0836 \\
(0.0000)\end{array}$ & $\begin{array}{l}-0.3169 \\
(0.0012)\end{array}$ & $\begin{array}{c}0.2484 \\
(0.0756)\end{array}$ & 0.6406 \\
\hline
\end{tabular}

No segundo teste de robustez relacionado ao BNDES, selecionamos a amostra de empresas financeiramente restritas apenas levando em consideração a obtenção de empréstimo junto ao BNDES ou não. Estimamos o modelo original, equação (2), e os resultados da estimação deste modelo estão apresentados na Tabela 8. Eles corroboram os apresentados na Tabela 6 acima. Mais uma vez, firmas que não possuem acesso às linhas de crédito de baixo custo junto ao BNDES dependem mais de recursos próprios para alavancarem seus projetos de investimento. 
Tabela 8 - Apenas Acesso ao Crédito do BNDES como Critério de Restrição Financeira A amostra é formada por um painel não balanceado de informações financeiras trimestrais de 168 empresas publicas brasileiras de 1986 a 2009. Este teste incluiu o critério de seleção "associação ao BNDES" ao Grupo 1. Aplicou-se o modelo de investimento adaptado para restrições financeiras utilizando regressão de dados em painel controlando para efeitos fixos de acordo com (2). A coluna $\mathrm{N}$ apresenta as quantidades que compõem o grupo de firmas comprovadamente associadas ao BNDES ou não. A coluna Q apresenta o coeficiente da regressão para o Q de Tobin. A coluna FC apresenta o coeficiente do fluxo de caixa. A coluna FC*FR destaca a importância do fluxo de caixa na explicação do investimento apenas para firmas financeiramente restritas. A coluna $\mathrm{R}^{2}$ apresenta o coeficiente de determinação do modelo para os grupos testados. Entre parênteses, temos os p-valores

\begin{tabular}{|c|c|c|c|c|c|c|c|}
\hline \multirow[b]{2}{*}{ Grupo } & \multirow[b]{2}{*}{ Critérios } & \multicolumn{2}{|c|}{$\mathbf{N}$} & \multirow[b]{2}{*}{$\mathbf{Q}$} & \multirow[b]{2}{*}{ FC } & \multirow[b]{2}{*}{$\mathbf{F C} * \mathbf{F R}$} & \multirow[b]{2}{*}{$\mathbf{R}^{2}$} \\
\hline & & $\mathrm{FC}$ & NFC & & & & \\
\hline 1 & Associação ao BNDES & 30 & 31 & $\begin{array}{c}-0.0360 \\
(0.0000)\end{array}$ & $\begin{array}{l}-0.4875 \\
(0.0000)\end{array}$ & $\begin{array}{c}0.2995 \\
(0.0001)\end{array}$ & 0.8248 \\
\hline
\end{tabular}

Finalmente, consideramos o fato de a empresa obter crédito junto ao BNDES apenas como um regressor e não mais como um critério de seleção. Sendo assim, estimamos o modelo original, equação (2), para os Gupos 1, 2 e 3 descritos anteriormente com a variável binária original FR (Financeiramente Restrita) substituída por uma variável binária BNDES, como na equação (5) abaixo. A variável BNDES é igual a quando a empresa obteve crédito e 0 em caso contrário.

$$
\left(\frac{I}{K}\right)_{i t}=\alpha+\beta_{1} \cdot Q_{i t}+\beta_{2} \cdot\left(\frac{F C}{K}\right)_{i t}+\beta_{3} \cdot F C_{i t} \cdot B N D E S_{i}+a_{i t}+\varepsilon_{i t}
$$

Os resultados, relatados na Tabela 9 abaixo, reforçam a importância do BNDES como fonte de financiamento de baixo custo para firmas que possuem acesso às suas linhas de crédito. Quando utilizado como variável binária para evidenciar a categoria financeiramente restrita, a associação ao BNDES apresenta resultados estatisticamente significativos na explicação do investimento corporativo para todos os grupos de firmas analisados.

\section{Tabela 9 - Incluindo a Variável Binária BNDES no Modelo Original}

A amostra é formada por um painel não balanceado de informações financeiras trimestrais de 168 empresas publicas brasileiras de 1986 a 2009. Este teste incluiu a variável binária BNDES como proxy para restrições financeiras em (2). Firmas comprovadamente não associadas ao Banco receberam o valor "1". Todas as outras firmas receberam o valor "0". A coluna $\mathrm{N}$ apresenta a totalidade de firmas que compõem os Grupos 1,2 e 3 . A coluna Q apresenta o coeficiente da regressão para o Q de Tobin. A coluna FC apresenta o coeficiente do fluxo de caixa. A coluna FC*BNDES destaca a importância do fluxo de caixa na explicação do investimento para firmas não associadas ao BNDES. A coluna $\mathrm{R}^{2}$ apresenta o coeficiente de determinação do modelo.

\begin{tabular}{clccccc}
\hline \hline Grupo & Critérios & $\mathbf{N}$ & $\mathbf{Q}$ & FC & FC*BNDES & $\mathbf{R}^{2}$ \\
\hline \multirow{2}{*}{1} & \multirow{2}{*}{ Tamanho } & \multirow{2}{*}{65} & -0.0063 & -0.6709 & 0.6164 & 0.7768 \\
& & & $(0.0000)$ & $(0.0000)$ & $(0.0000)$ & \\
& \multirow{2}{*}{ Distribuição de Dividendos } & \multirow{2}{*}{168} & -0.0092 & -0.3953 & 0.3848 & 0.6938
\end{tabular}


Emissão de Títulos

2

Tamanho / Distribuição de

Dividendos

3

Tamanho / Distribuição de

Dividendos / Emissão de Títulos

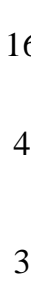

168

45

36

$\begin{array}{ll}-0.0088 & -0.5878 \\ (0.0000) & (0.0000) \\ -0.0063 & -0.7004 \\ (0.0000) & (0.0000) \\ & \\ -0.0054 & -0.7255 \\ (0.0006) & (0.0000)\end{array}$

0.5773

(0.0000)

0.6701

$(0.0000)$

0.7110

(0.0000)

Como último teste de robustez, resolvemos incluir uma dinâmica na especificação original, equação (2), da demanda de investimento. Para tanto, acrescentamos como regressor o quociente entre investimento e o estoque de capital defasado em um período. Para estimar este modelo, utilizamos GMM com efeito fixo.

Os resultados estão apresentados nas Tabelas 10 e 11 abaixo. Como podemos verificar, eles são, de maneira geral, semelhantes àqueles que obtivemos com a estimação inicial (equação (2)) e confirmam a relevância do fluxo de caixa e, portanto, de restrições de crédito para explicar a demanda de investimento por parte de firmas públicas brasileiras em nossa amostra.

\section{Tabela 10 - Análise de Painel não balanceado para os Grupos 1, 2 e 3 usando GMM Efeito Fixo.}

A amostra é formada por um painel não balanceado de informações financeiras trimestrais de 168 empresas publicas brasileiras de 1986 a 2009. O modelo foi estimado com GMM efeito fixo. Como instrumento, usamos a segunda defasagem da variável dependente.

\begin{tabular}{|c|c|c|c|c|c|}
\hline Grupo & Critérios & $\mathbf{N}$ & $\mathbf{Q}$ & FC & FC*FR \\
\hline \multirow{3}{*}{1} & Tamanho & 65 & $\begin{array}{c}-0.000441 \\
(0.4434)\end{array}$ & $\begin{array}{c}-0.125592 \\
(0.0000)\end{array}$ & $\begin{array}{c}0.105234 \\
(0.0000)\end{array}$ \\
\hline & Distribuição de Dividendos & 168 & $\begin{array}{c}-0.000557 \\
(0.3469)\end{array}$ & $\begin{array}{c}-0.008157 \\
(0.1181)\end{array}$ & $\begin{array}{c}0.010778 \\
(0.2778)\end{array}$ \\
\hline & Emissão de Títulos & 168 & $\begin{array}{c}-0.000540 \\
(0.3623)\end{array}$ & $\begin{array}{c}-0.022136 \\
(0.0025)\end{array}$ & $\begin{array}{c}0.027046 \\
(0.0033)\end{array}$ \\
\hline 2 & $\begin{array}{l}\text { Tamanho / Distribuição de } \\
\text { Dividendos }\end{array}$ & 45 & $\begin{array}{c}0.003253 \\
(0.0114)\end{array}$ & $\begin{array}{c}-0.078335 \\
(0.0111)\end{array}$ & $\begin{array}{r}0.083857 \\
(0.0085)\end{array}$ \\
\hline 3 & $\begin{array}{l}\text { Tamanho / Distribuição de } \\
\text { Dividendos / Emissão de Títulos }\end{array}$ & 36 & $\begin{array}{c}0.003363 \\
(0.0047)\end{array}$ & $\begin{array}{c}-0.048874 \\
(0.0609)\end{array}$ & $\begin{array}{c}0.053753 \\
(0.0447)\end{array}$ \\
\hline
\end{tabular}

\section{Tabela 11- GMM Painel incluindo variável dummy de crises econômicas sobre as} restrições no acesso ao crédito.

A amostra é formada por um painel não balanceado de informações financeiras trimestrais de 168 empresas publicas brasileiras de 1986 a 2009. O modelo foi estimado com GMM efeito fixo. Como instrumento, usamos a segunda defasagem da variável dependente. 


\begin{tabular}{|c|c|c|c|c|c|c|}
\hline Grupo & Critérios & $\mathbf{N}$ & $\mathbf{Q}$ & $\mathbf{F C}$ & FC*FR & FC*CRISES \\
\hline \multirow{3}{*}{1} & Tamanho & 65 & $\begin{array}{l}-0.0004 \\
(0.4208)\end{array}$ & $\begin{array}{l}-0.1226 \\
(0.0000)\end{array}$ & $\begin{array}{c}0.1043 \\
(0.0000)\end{array}$ & $\begin{array}{l}-0.0077 \\
(0.5105)\end{array}$ \\
\hline & Distribuição de Dividendos & 169 & $\begin{array}{c}-0.0004 \\
(0.5155)\end{array}$ & $\begin{array}{c}-0.0476 \\
(0.0000)\end{array}$ & $\begin{array}{c}0.0469 \\
(0.0001)\end{array}$ & $\begin{array}{c}0.0579 \\
(0.0000)\end{array}$ \\
\hline & Emissão de Títulos & 168 & $\begin{array}{c}0.0066 \\
(0.0000)\end{array}$ & $\begin{array}{l}-0.0362 \\
(0.0000)\end{array}$ & $\begin{array}{c}0.0324 \\
(0.0002)\end{array}$ & $\begin{array}{c}0.0221 \\
(0.0084)\end{array}$ \\
\hline 2 & Tamanho / Distribuição de Dividendos & 45 & $\begin{array}{c}0.0032 \\
(0.0114)\end{array}$ & $\begin{array}{l}-0.0725 \\
(0.0351)\end{array}$ & $\begin{array}{c}0.0780 \\
(0.0272)\end{array}$ & $\begin{array}{l}-0.0167 \\
(0.6940)\end{array}$ \\
\hline 3 & $\begin{array}{l}\text { Tamanho / Distribuição de Dividendos / } \\
\text { Emissão de Títulos }\end{array}$ & 36 & $\begin{array}{c}0.0033 \\
(0.0047)\end{array}$ & $\begin{array}{l}-0.0370 \\
(0.2076)\end{array}$ & $\begin{array}{c}0.0419 \\
(0.1640)\end{array}$ & $\begin{array}{l}-0.0355 \\
(0.4040)\end{array}$ \\
\hline
\end{tabular}

\section{CONCLUSÃO}

Este trabalho analisou empiricamente o investimento corporativo em presença de imperfeições de mercado aplicando um modelo empírico derivado de FHP (1988) a uma base de dados de informações financeiras trimestrais de 168 empresas brasileiras de capital aberto entre os anos de 1986 e 2009.

Classificamos as firmas entre mais ou menos restritas financeiramente de acordo com a interseção dos principais critérios propostos pela literatura. Selecionamos três dos principais critérios utilizados em trabalhos anteriores - tamanho das firmas, taxa de distribuição de dividendos e acesso ao mercado de emissão de títulos - e construímos conjuntos de dados contendo as firmas que satisfizeram apenas um, dois ou os três critérios estabelecidos simultaneamente.

Nossos resultados revelaram a importância do fluxo de caixa na explicação do investimento das firmas mais restritas financeiramente para os três grupos analisados. Estas são significativamente mais dependentes de recursos próprios para financiarem seus projetos de investimento.

Adicionalmente, este artigo ainda investigou a influência de crises econômicas e da obtenção de crédito da firma junto ao BNDES no que diz respeito ao investimento das empresas brasileiras. Quanto às crises financeiras, nossos resultados indicam que a diminuição nos níveis de concessão de crédito nos períodos de crises enfrentados pelo país nos últimos 15 anos, afetou de forma geral as demandas de investimento das empresas utilizadas no trabalho e classificadas quanto aos diferentes níveis de restrição financeira ${ }^{20}$.

\footnotetext{
${ }^{20}$ Hipótese válida para os critérios de seleção utilizados no trabalho (tamanho das firmas, taxa de distribuição de dividendos e acesso ao mercado de emissão de títulos.
} 
No que diz respeito ao BNDES, há evidências que ele é uma fonte de recursos importante no cenário nacional para as empresas públicas e que há diferenças significativas na demanda de investimentos das firmas que possuem ou não acesso às suas linhas de crédito de baixo custo. Essas diferenças no acesso ao mercado financeiro entre empresas mais e menos restritas financeiramente têm muitas razões possíveis. Entre elas, podemos citar: uma legislação de falência que torna difícil para os credores retomar o crédito concedido; os altos spreads que ainda prevalecem no Brasil especialmente para empresas mais restritas e um mercado de crédito segmentado, em que o financiamento de longo prazo para investimento vem basicamente do BNDES, e onde o acesso é muito fácil para as grandes empresas, em princípio, aquelas que são menos restritas financeiramente.

Uma limitação importante de nosso estudo é analisar apenas empresas listadas abertas. Cremos que empresas privadas fechadas são naturalmente mais restritas a crédito do que aquelas. Portanto, uma possível extensão para trabalhos futuros seria construir uma base de dados de empresas fechadas e abertas e aplicar a metodologia usada neste artigo para esta base de dados. 


\section{REFERÊNCIAS}

ALMEIDA, Heitor; CAMPELLO, Murillo; WEISBACH. The Cash Flow Sensitivity of Cash. Journal of Finance, v. 59, p. 1777-1804, 2004.

ALLAYANNIS, G. \& MOZUMDAR, A. 2004. The impact of negative cash flow and influential observations on investment-cash flow sensitivity estimates.

Journal of Banking \& Finance, 28, 2004, 901-930 .

ALTI, A. How Sensitive Is Investment to Cash Flow When Financing Is Frictionless? The Journal of Finance, 58, 707-722, 2003.

AGCA, S.; MOZUMDAR, A. The impact of capital market imperfections on investment-cash flow sensitivities. Journal of Banking and Finance, n. 32, 2008. 207-216.

AGGARWAL, R.; ZONG, S. The cash flow-investment relationship: International evidence of limited access to external finance. Journal of Multinational Financial Management, n. 16, 2006. 89-104.

AKERLOF, G. A. The Market For "Lemons": Quality Uncertainty And The Market Mechanism. Quarterly Journal of Economics, 84, Ago 1970. 488-500.

ALLAYANIS, G.; MOZUMDAR, A. The impact of negative cash flow and infuential observations on investment-cash flow sensitivity estimates. Journal of Banking and Finance, n. 28, 2004. 901-930.

ASCIOGLU, A.; HEGDE, S. P.; MCDERMOTT, J. B. Information asymmetry and investment-cash flow sensitivity. Journal of Banking and Finance, 2008. 1036-1048.

BERNANKE, B.; GERTLER, M.; GILCHRIST, S. The Financial Accelerator And The Flight To Quality. Review of Economics \& Statistics, 78, Fev 1996. 1-15.

BHADDURI, S. Investment and Capital Market Imperfections: Some Evidence from a Developing Economy, India. Review of Pacific Basin Financial Markets and Policies, 11, n. 3, 2008. 411-428.

BHAGAR, S.; MOYENA, N.; SUH, I. Investment and internal funds of distressed firms. Journal of Corporate Finance, 2005. 449-472.

BLOCH, C. R\&D Investment and Internal Finance: The Cash Flow Effect. Economics of Innovation and New Technology, 14, n. 3, Abril 2005. 213-223.

BLUNDELL, R. et al. Investment and Tobin's Q. Journal of Econometrics, v. 51, n. 1, p. 233-257, Jan 1992.

BNDES. Consulta às operações diretas com empresas - BNDES. BNDES - O Banco Nacional do Desenvolvimento. Disponivel em: 
<http://www.bndes.gov.br/SiteBNDES/bndes/bndes_pt/Institucional/BNDES_Transparente/C onsulta_as_operacoes_do_BNDES/setorprivado.html>. Acesso em: 15 ago. 2010.

BOBILLO, A.; SANZ, J.; GAITE, F. Investment Decisions, Liquidity and Institutional Activism: An International Study. Journal of Business Ethics, 87, 2009. 25-40.

BOND, S.; MEGHIR, C. Dynamic investment models and the firm's financial policy. Review of Economic Studies, v. 61, n. 207, p. 197-223, Abr 1994.

BROWN, J.; PETERSEN, B. Why has the investment-cash flow sensitivity declined so sharply? Rising R\&D and equity market developments. Journal of Banking \& Finance, 33,2009. 971-984.

BROWN, J.; PETERSEN, B. Public entrants, public equity finance and creative destruction. Journal of Banking \& Finance, 34, 2010. 1077-1088.

CALOMIRIS, C. W.; HIMMELBERG, C. P.; WACHTEL, P. Commercial Paper, Corporate Finance, and the Business Cycle: A Microeconomic Perspective. NBER Working Paper No. W4848, Set 1994.

CARPENTER, R. E.; FAZZARI, S. M.; PETERSEN, B. C. Inventory Investment, InternalFinance Fluctuations, and the Business Cycle. Brookings Papers on Economic Activity, n. 2, p. 75-138, 1994.

CRISÓSTOMO, V. L. Dificuldades das empresas brasileiras para financiar seus investimentos em capital físico e em inovação. Revista de Economia Contemporânea, v. 13, p. 259-280, 2009.

CHIRINKO, R. S. Business Fixed Investment Spending: Modeling Strategies, Empirical Results, and Policy Implications. Journal of Economic Literature, v. 31, n. 4, p. p18751911, 93.

CHIRINKO, R. S. Multiple capital inputs, Q, and investment spending. Journal of Economic Dynamics \& Control, v. 17, n. 5/6, p. p907, Sep/Nov 93.

CHOW, C.; SONG, F.; KIT, W. Investment and the soft budget constraint in China. International Review of Economics and Finance, 19, 2010. 219-227.

COSTA, Cristiano M.; PAZ, Lourenço Senne; FUNCHAL, Bruno. Are Brazilian Firms Savings Sensitive to Cash Windfalls? Brazilian Business Review, v. 5, n. 2, p. 136-142, Mar/Aug. 2008.

CLEARY, S. International corporate investment and the relationships between financial constraint measures. Journal of Banking \& Finance, 30, 2006. 1559-1580.

DASGUPTA, S.; SENGUPTA, K. Corporate liquidity, investment and financial constraints: Implications from a multi-period model. Journal of Financial Intermediation, 16, 2007. 151-174. 
DEGRYSE, J.; DE JONG, A. Investment and internal finance: Asymmetric information or managerial discretion? Internation Journal of Industrial Organization, 24, 2006. 125-147.

D`ESPALlIER, Bert; VANDEMAELE, Sigrid; PEETERS, Ludo. Investment-Cash Flow Sensitivities or Cash-Cash Flow Sensitivities? An Evaluative Framework for Measures of Financial Constraints. Journal of Business Finance \& Accounting, v. 35, n. 7-8, p. 943-968, sep./oct. 2008.

ELLIOT, J. W. Theories of Corporate Investment Behavior Revisited. American Economic Review, v. 63, p. 195-207, Março 1973.

ESTEVES FILHO, M.; NESS JR., W. L. Restrições Financeiras Aos Investimentos Fixos De Empresas Brasileiras Listadas Em Bolsa De Valores No Período De 1995 A 2003. V Encontro Brasileiro de Finanças. São Paulo: SBFin - Sociedade Brasileira de Finanças. 2005. p. 25.

FAMA, E. F.; FRENCH, K. R. Testing Trade-Off and Pecking Order Predictions About Dividends and Debt. Review of Financial Studies, 15, Out 2002. 1-33.

FAZZARI, S. M.; HUBBARD, R. G.; PETERSEN, B. C. Financing Constraints and Corporate Investment. Brookings Papers on Economic Activity, 1988. 141-206.

FAZZARI, S. M.; PETERSEN, B. C. Working capital and fixed investment: New evidence on financing constraints. RAND Journal of Economics, v. 24, n. 3, p. 328-342, Out 1993.

GILCHRIST, S.; HIMMELBERG, C. P. Evidence on the role of cash flow for investment. Journal of Monetary Economics, v. 36, n. 3, p. 541-573, Dez 1995.

HAYASHI, F. Tobin's Marginal Q And Average Q: A Neoclassical Interpretation. Econometrica, v. 50, n. 1, p. p213-224, Jan 1982.

HOSHI, T.; KASHYAP, A. Corporate Structure, Liquidity And Investment: Evidence From Japanese Industrial Groups. Quarterly Journal of Economics, 106, n. 1, Fev 1991. 33-60.

HOSHI, T.; KASHYAP, A.; SCHARFSTEIN, D. Corporate Structure, Liquidity, And Investment: Evidence From Japanese Industrial Groups. Quarterly Journal of Economics, 106, n. 1, Fev 1991. 33-60.

HU, X.; SCHIANTARELLI, F. Investment And Capital Market Imperfections: A Switching Regression Approach Using U.S. Firms Panel Data. Review of Economics \& Statistics, 80, n. 3, Agosto 1998. 466-480.

HUBBARD, R. G. Capital-market imperfections and investment. Journal of Economic Literature, v. 36, n. 1, p. p193-225, Março 1998.

JORGENSON, D.; HALL, R. Tax Policy and Investment Behavior. American Economic Review, v. 57, n. 3, p. 391-414, Junho 1967. 
JORGENSON, D.; SIEBERT, C. A Comparison of Alternative Theories of Corporate Investment Behavior. American Economic Review, v. 58, p. 681-712, Setembro 1968.

KAPLAN, S. N.; ZINGALES, L. Do Investment-Cash Flow Sensitivities Provide Useful Measures Of Financing Constraints? Quarterly Journal of Economics, 112, Fev 1997. 169215.

KIRCH, Guilherme; TERRA, P. R. S.; PROCIANOY, Jairo L. Restrições ao Crédito, Tangibilidade e Decisões de Investimento. In. ENCONTRO BRASILEIRO DE FINANÇAS, X, 2010, São Paulo. Anais SBFIN, São Paulo, 2010.

MECKLING, W. H.; JENSEN, M. C. Theory of the Firm: Managerial Behavior, Agency Costs and Ownership Structure. Journal of Financial Economics, 4, n. 3, Outubro 1976. 305-360.

MEYER, J.; KUH, E. The Investment Decision: an empirical study. Cambridge: Harvard University Press, 1957.

MODIGLIANI, F.; MILLER, M. H. The cost of capital, corporate finance and the theory of investment. The American Economic Review, June 1958. 261-297.

MYERS, S. C. The Capital Structure Puzzle. The Journal of Finance, 39, Jul 1984. 575-592.

MYERS, S. C.; MAJLUF, N. S. Corporate Financing And Investment Decisions When Firms Have Information That Investors Do Not Have. Journal of Financial Economics, 13, Jun 1984. p187-221.

NESS JR, W. L. ; ESTEVES Filho, Mário . Restrições financeiras aos investimentos fixos de empresas brasileiras listadas em bolsa de valores no período de 1995 a 2003. In: 50 Encontro Brasileiro de Finanças, 2005, São Paulo. Anais, 2005.

NOVAES, Walter e MARTINS, Cotrin, Theo. Mandatory dividend rules: Do they make it harder for firms to finance investment opportunities. Em: Financial Economics in Rio. Anais, 2010.

OLIVEIRA, N. F. . Effects of Monetary Policy on Firms in Brazil: Na Empirical Analyses of the Balance Sheet Channel. Brazilian Review of Econometrics, vol 29, No 2, 2009, 171-204.

PORTAL, Márcio Telles; ZANI, João; SCHONERWALD, Carlos E. Fricções Financeiras e Substituição entre Fundos Internos e Externos. In. ENCONTRO BRASILEIRO DE FINANÇAS, XI, 2011, São Paulo. Anais SBFIN, São Paulo, 2011.

SCHALLER, H. Asymmetric information, liquidity constraints, and Canadian investment. Canadian Journal of Economics, v. 26, n. 3, p. 552-575, 1993.

TERRA, Maria Cristina T. Credit Constraints in Brazilian Firms: Evidence from Panel Data. Revista Brasileira de Economia, p. 443-464, Abr/jun 2003.

TOBIN, J. A General Equilibrium Approach to Monetary Theory. Journal of Money, Credit, and Banking, v. 1, p. 15-29, 1969. 
WIKIPEDIA. Deductive reasoning, 26 abr. 2010. Disponivel em: <http://en.wikipedia.org/wiki/Deductive_reasoning>. Acesso em: 26 abr. 2010.

WIKIPEDIA. Neoclassical economics - Wikipedia, the free encyclopedia, 18 abr. 2010. Disponivel em: <http://en.wikipedia.org/wiki/Neoclassical_economics>. Acesso em: 26 abr. 2010.

ZANI, João; PROCIANOY, Jairo Laser. Restrição Financeira da Firma: A Variação na Estocagem de Liquidez Determinada pelos Status Financeiro e pela Geração de Caixa Operacional. In: ENCONTRO BRASILEIRO DE FINANÇAS, 5, 2005, São Paulo. Anais SBFIN, São Paulo, 2005. 


\begin{tabular}{|c|c|c|c|c|c|}
\hline $\begin{array}{l}\text { Anexo A Critérios de } \\
\text { Restrição Financeira }\end{array}$ & & & & & \\
\hline Referência & Período & Frequência & Tamanho (firmas) & Fonte & Critério de Seleção \\
\hline $\begin{array}{l}\text { Fazzari, Hubbard e } \\
\text { Petersen (1988) }\end{array}$ & $1970-1984$ & Anual & 421 & Value Line & $\begin{array}{c}\text { Taxa de distribuição de } \\
\text { dividendos }\end{array}$ \\
\hline $\begin{array}{l}\text { Bernanke, Gertler e } \\
\text { Gilchrist (1996) }\end{array}$ & 1977-1994 & Trimestral & - & $\begin{array}{l}\text { Quarterly Financial } \\
\text { Reports }\end{array}$ & $\begin{array}{c}\text { Tamanho } \\
\text { Acesso ao mercado de } \\
\text { commercial papers } \\
\text { Composição da dívida }\end{array}$ \\
\hline Esteves e Ness (2003) & $1995-2003$ & Anual & 160 & $\begin{array}{l}\text { Economática, SABE, } \\
\text { CVM e Bovespa }\end{array}$ & $\begin{array}{l}\text { Tamanho } \\
\text { Taxa de distribuição de } \\
\text { dividendos } \\
\text { Acúmulo de estoques } \\
\text { Níveis de endividamento } \\
\text { Nacionalidade }\end{array}$ \\
\hline $\begin{array}{l}\text { Blundell, Bond, Devereux } \\
\text { e Schiantarelli (1992) }\end{array}$ & $1968-1986$ & Anual & 532 & $\begin{array}{c}\text { DataStream International } \\
\text { e London Share Price } \\
\text { Database }\end{array}$ & $\begin{array}{l}\text { Segmentos da indústria de } \\
\text { manufatura }\end{array}$ \\
\hline Bond e Meghir (1994) & $1974-1986$ & Anual & 626 & Datastream International & $\begin{array}{l}\text { Segmentos da indústria de } \\
\text { manufatura }\end{array}$ \\
\hline $\begin{array}{l}\text { Carpenter, Fazzari e } \\
\text { Petersen (1994) }\end{array}$ & $1982-1991$ & Trimestral & - & Compustat & Tamanho \\
\hline $\begin{array}{l}\text { Hoshi, Kashyap e } \\
\text { Scharfstein (1991) }\end{array}$ & $1965-1986$ & Anual & 165 & $\begin{array}{l}\text { Tokyo Stock Exchange } \\
\text { Nikkei Financial Data } \\
\text { Tapes } \\
\text { Keiretsu no Kenyu } \\
\text { Industrial Groupings in } \\
\text { Japan }\end{array}$ & $\begin{array}{c}\text { Associação a grandes } \\
\text { conglomerados industriais } \\
\text { japoneses }\end{array}$ \\
\hline Fazzari e Petersen (1993) & $1970-1979$ & Anual & - & Value Line & $\begin{array}{l}\text { Taxa de distribuição de } \\
\text { dividendos }\end{array}$ \\
\hline $\begin{array}{c}\text { Gilchrist e Himmelberg } \\
\text { (1995) }\end{array}$ & $1979-1989$ & Anual & 428 & $\begin{array}{l}\text { Standard \& Poor's } \\
\text { Compustat }\end{array}$ & $\begin{array}{l}\text { Taxa de distribuição de } \\
\text { dividendos } \\
\text { Tamanho das firmas } \\
\text { Classificação de títulos } \\
\text { Acesso ao mercado de } \\
\text { commercial papers }\end{array}$ \\
\hline
\end{tabular}




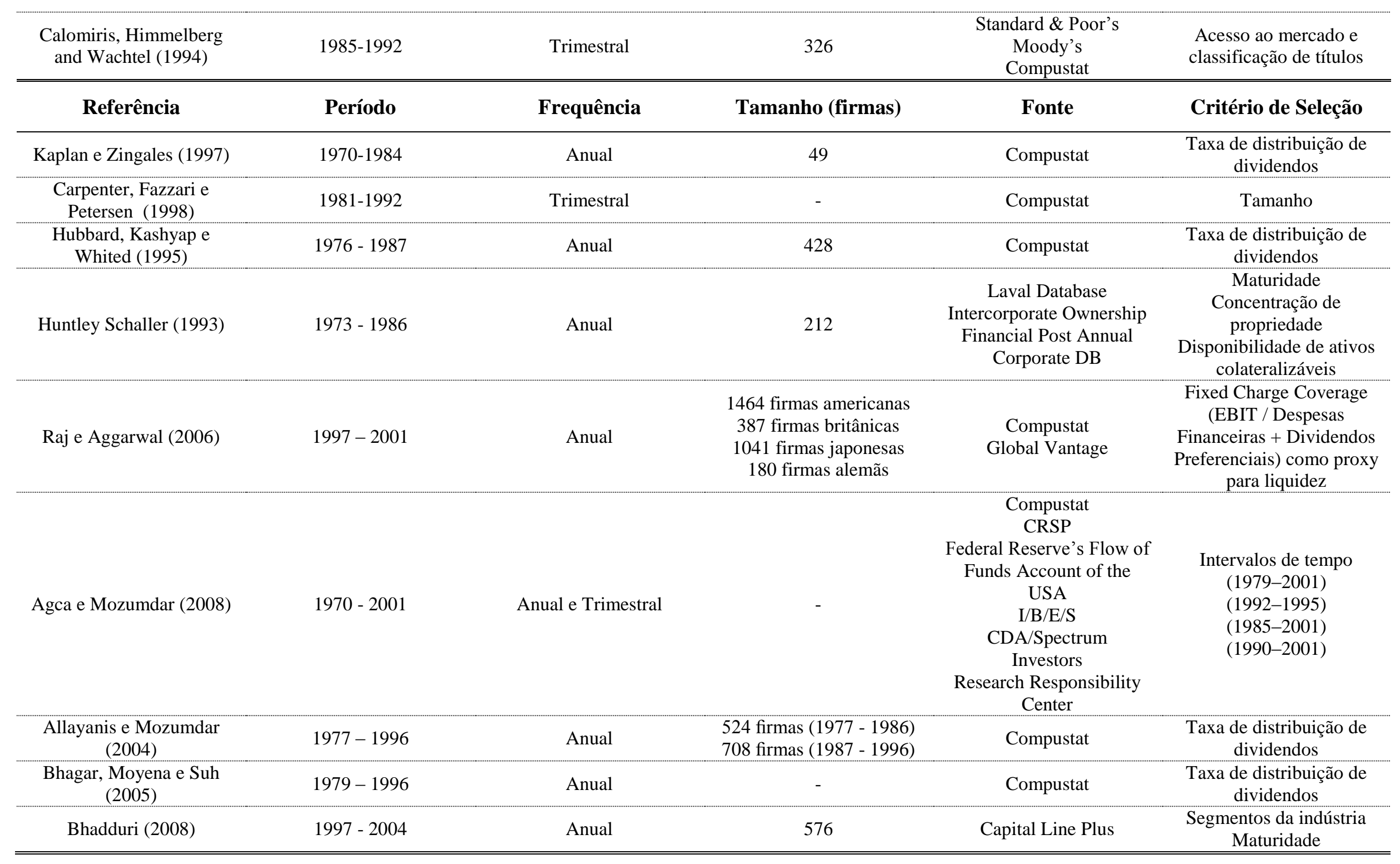




\begin{tabular}{|c|c|c|c|c|c|}
\hline Referência & Período & Frequência & Tamanho (firmas) & Fonte & Critério de Seleção \\
\hline $\begin{array}{l}\text { Ascioglu, Hegde e } \\
\text { Mcdermott (2008) }\end{array}$ & $2000-2003$ & Anual & $\begin{array}{l}509 \text { firmas (2000) } \\
483 \text { firmas }(2003)\end{array}$ & $\begin{array}{c}\text { CRSP } \\
\text { NYSE TAQ } \\
\text { Compustat }\end{array}$ & $\begin{array}{l}\text { Taxa de distribuição de } \\
\text { dividendos }\end{array}$ \\
\hline Bloch (2005) & 1989-2001 & Anual & 63 firmas & $\begin{array}{l}\text { Copenhagen Stock } \\
\text { Exchange }\end{array}$ & $\begin{array}{l}\text { Segmentos da indústria } \\
\text { Tamanho } \\
\text { Composição da dívida } \\
\text { Investimento em P\&D }\end{array}$ \\
\hline $\begin{array}{l}\text { Bobillo, Sanz e Gaite } \\
\text { (2009) }\end{array}$ & 1995-2004 & Anual & $\begin{array}{l}3535 \text { firmas do Reino } \\
\text { Unido, França, Espanha, } \\
\text { Dinamarca e Alemanha }\end{array}$ & $\begin{array}{c}\text { Compustat } \\
\text { Amadeus } \\
\text { Bases estatísticas oficiais } \\
\text { do Reino Unido, França, } \\
\text { Espanha, Dinamarca e } \\
\text { Alemanha }\end{array}$ & $\begin{array}{l}\text { Participação acionária e } \\
\text { controle institucional }\end{array}$ \\
\hline Brown e Petersen (2009) & $1970-2006$ & Anual & 1851 firmas & Compustat & Maturidade \\
\hline Brown e Petersen (2010) & 1970-2004 & Anual & 1786 firmas & $\begin{array}{c}\text { Thompson Financial's } \\
\text { SDC New Issues database } \\
\text { Compustat }\end{array}$ & $\begin{array}{l}\text { Segmentos da indústria de } \\
\text { manufatura }\end{array}$ \\
\hline Chow, Song e Kit (2010) & $1997-2003$ & Anual & 1173 firmas & $\begin{array}{l}\text { China Stock Market \& } \\
\text { Accounting Research } \\
\text { (CSMAR) }\end{array}$ & $\begin{array}{c}\text { Participação acionária do } \\
\text { Estado Chinês }\end{array}$ \\
\hline Cleary (2006) & 1987-1997 & Anual & $\begin{array}{l}4095 \text { firmas dos EUA, } \\
\text { Reino Unido, Japão, } \\
\text { Alemanha, França, } \\
\text { Canadá e Austrália }\end{array}$ & Global Vantage & $\begin{array}{c}\text { Tamanho } \\
\text { Taxa de distribuição de } \\
\text { dividendos }\end{array}$ \\
\hline Degryse e De Jong (2006) & 1993-1998 & Anual & 132 firmas holandesas & $\begin{array}{c}\text { Statistics Netherlands } \\
\text { Amsterdam Stock } \\
\text { Exchange } \\
\text { Het Financieele Dagblad } \\
\text { Yearbook of Dutch } \\
\text { Companies } \\
\end{array}$ & $\begin{array}{l}\text { Tamanho } \\
\text { Segmento da indústria } \\
\text { Maturidade }\end{array}$ \\
\hline
\end{tabular}




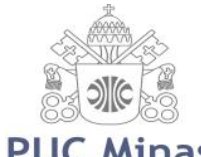
PUC Minas
E\&G - REVISTA ECONOMIA E GESTÃO

$\mathrm{E}_{2} \mathrm{G}$ 